liar, and never to be forgotten. The purging is an incessant squirting of this foul fluid. If any doubt exist, let a dose of quinine and iron be given, and the disgust expressed will attest the nature of the attack. The other diagnostic signs are, that there is always some fur on the tongue, the pulse is generally perceptible, and the heart's action very rapid and feeble; not convulsively struggling and churning as in congestive cholera. Add to this that some urine is generally. secreted, the extremities are not so cold as in the congestive disease, nor does the same amount of warmth return to them when death takes place. The previous history of the attack is, that the patient has been purged perhaps a dozen times within a few hours; at first the tongue was red and much furred, the mouth hot, the skin warm, the pulse above a hundred and sharp; then sickness came on and cramps, the skin grew cold and damp, and, exhausted by continued purging, he has fallen into the state of collapse.

It is, in the first place, of importance here to remark, that there is nothing of that oppression of the heart's action by excess of blood on the right side, and deficiency of it on the left, which to relieve is to cure, in the congestive form of cholera.

The continued purging, which is here a secretion, not an exudation, prevents that overdistension of the great venous trunks of the cava and portal system taking place, which obstructs secretion. In short, it is not venous congestion and paralysis of action in the capillaries that we have to contend with here, but a draining away of the life by the quantity of fluid poured into the bowels under the influence of the putrid irritant into which the whole of the mucus of the intestines has been converted. It is in vain that we here attack the algide symptoms, for even were we successful in restoring animal heat, etc., the cause remains; and as long as mucus continues to be secreted into the bowels, the purging will continue unless the putrefactive action be arrested.

It seems probable that large draughts of finely powdered peat charcoal in water will ultimately be found the best cure for this malady. Dr. Johnson uses castor oil, which answers very well if repeated sufficiently perseveringly to evacuate the decomposing mucus as quickly as it is formed. Tartar emetic in combination with calonel answers very well, or calomel alone in repeated doses, where it acts both directly as an antiseptic and in the same purgative way as castor oil. Dilute sulphuric acid drink is purely antiseptic in its operations; so is salt; and cases are mentioned where an immense draught of spirits has cured. If by any of these means the putrescent action is arrested and the purging stopped, warmth gradually returns to the surface, and the algide symptoms disappear.

It may be observed, that correct diagnosis alone can direct the cure here, for to attempt this by the means which afford the greatest relief to patients suffering from the congestive or true form of the disease only aggravates; and indeed the expression of disgust and horror exhibited by patients in the algide state of cholera induced by putrid diarrhœa when offered a second dose of solution of quinine and iron, is in perfect contrast to the thankfulness with which a similar dose is swallowed by one in the congestive stage of true cholera.

Of the bilious form of diarrhœa after algide symptoms have been superinduced, I find innumerable cases cited by Indian authorities, for example, 'Twining, Parkes, and others. In the first stage the attack is identical with that which, were cholera absent, would turn to dysentery; and most of the protracted cases exhibit dysenteric symptoms, if the algide stage be reco. vered from, along with remittent or so-called consecutive fever. Here there is no very leading symptom, unless it be the presence of a very little fur on the tongue, which is never seen in pure congestive cholera, and the absence of putrid odour on throwing down the bedclothes. The purging is very considerable in quantity, generally colourless and without smell, save when occasionally it contains bile. The treatment here is strictly that applicable to acute dysentery : calomel and opium, ipecacuanha, sugar of lead and opium, etc. Mere antiseptics, like dilute sulphuric acid, do no good; and the draught of quinine and iron, though not producing the intensity of disgust that it does in cases of putrid diarrhoea, is disagreeable to the patient, and is attended with none of the sensations of comfort and relief afforded by its exhibition in purely congestive cholera. In these cases all the adjuncts of treatment by hot air baths, stimulants, etc., may be found of value which in true congestive cholera are exactly the reverse : perhaps where the distinction is otherwise difficult, the tolerance of warm applications in the one case, and their extreme intolerance in the other, might serve as a test.

This is all that it has appeared necessary to premise respect- ing the diseases, which, though distinct from cholera in their essence, most frequently lead into it. Practically, they may perhaps be deemed of even greater importance than the unmixed congestive or primary disease, as being numerically more fatal.

[To be continued.]

\section{ON A POSSIBLE CAUSE OF THE FIRST SOUND OF THE HEART.}

By John Cockle, A.M., M.D.

I Have frequently meditated upon the assertion of Bartholini, made in his Anatomy, published in 1673, page 379, that the ligation of the venæ cavæ arrested the action of the heart. $\mathrm{He}$ writes: "Unico experimento fidem assertione facio, si vinculo intercipiantur vasa cordis adferentia motus cordis desinit, reliquusque erit undulans tantum motus et palpitatio, soluta ligatura motum recipit. Recentiores curiosi novo experimento nos confirmant."

Haller (Observation sur la Cause du Mouvement du Cour, 1751 ), in repeating this experiment, found, that unless the cava were opened, and the right auricle emptied, the motion of the heart was not always arrested, but that with the precaution in dicated the experiment was always successful.

These experiments then, in warm-blooded animals, fully demonstrate the presence of blood in the auricle to be the sine qua non of the heart's perfect systolic and diastolic motion.

Dr. Halford has more recently shown, by well devised experiment, that if the cavæ are compressed, although the heart's action continues vigorous, yet upon the application of the stethoscope "no sound whatever is heard."

I venture to suggest, therefore, taking these experiments as a basis, supported by others of my own, which I shall make the subject of a future paper, that the first sound may be principally produced in the following manner. During, at least, part of the time of the ventricular systole, the auriculoventricular valves are closed by the pressure of the column of blood impelled against them; but by the time the valves are brought to the plane of closure, the dilating auricles have allowed the blood streaming from the cavæ and pulmonary veins to form a layer upon the upper surface of the valves; and it is, I conceive, by the reaction of the lower column of blood upon the superimposed layer, the valve intervening that the special character of the first sound is produced. The modifications of the sound, in part, depending upon the varying quantity of blood entering the cavity of the auricles.

63, Brook Street, Grosvenor Square, January 24th, 1857.

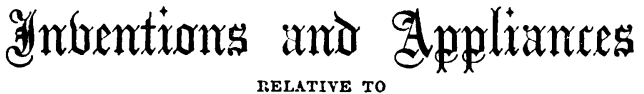

MEDICINE AND SURGERY.

\section{BOURJEAURD'S ELASTIC APPARATUS.}

THE difficulty of applying pressure, when required, to any part of the body, in such a way that it shall fully effect the object desired, without either positively or negatively doing mischief either to the parts under treatment or to those in their vicinity, has long been a source of annoyance to surgeons. Hence systematic writers on surgery are accustomed to lay down precise instructions as to the mode of bandaging a limb; and, in medical schools, a special course of instruction on this important branch of surgical practice is sometimes given.

In recent years, surgeons and mechanicians have endeavoured to make application of the elastic property of certain substances in this direction, and especially of caoutchouc or India rubber. Of those who have devoted their attention to this subject, Mr. BourJeaturd holds the most prominent position, and has contrived a number of elastic appliances which, although they may, on further experience, be found capable of improvement in some of their details, yet far surpass in efficiciency and safety the means formerly in use. It is right here to state, that Mr. Bourjeaurd has the advantage of not being a mere amateur mechanician; he is, in fact, a member of the 